\section{Culture Fair Test}

Glen E. Getz

Department of Psychiatry, Allegheny General Hospital, Pittsburgh, PA, USA

\section{Synonyms}

Culturally reduced test; Culture free test

\section{Definition}

Culture fair test is a test that is equally fair to all cultural groups. Fairness is related to a lack of bias in the interpretation or use of a test to classify or diagnose. In a culture fair test, the validity of the interpretation is similar across different cultural groups. It is unlikely that any test can entirely eliminate the influence of learning and cultural experience, given that the test content, language, directions, and validity criteria are culturally bound. However, avoiding culturally loaded items, items that are found to be unfair to certain groups of people, increases the likelihood of it being a culturally fair test. Culturally loaded items, such as those that utilize pictures or general information that are differentially prevalent for certain cultures, decrease the likelihood of a culturally fair test.

\section{Cross-References}

Cultural Sensitivity

- Raven's Progressive Matrices

\section{References and Readings}

Jensen, A. R. (1974). How biased are culture-loaded tests? Genetic Psychology Monographs, 90, 185-244.

Scarr, S. (1994). Culture fair and culture free test. In R. J. Sternberg (Ed.), Encyclopedia of human intelligence. New York: Macmillan. 